\title{
Electronically Tunable TISO Voltage-Mode Universal Filter Using Two LT1228s
}

\author{
May Phu Pwint Wai*, Winai Jaikla, Surapong Siripongdee, \\ Amornchai Chaichana, Peerawut Suwanjan \\ Department of Engineering Education, School of Industrial Education and Technology, \\ King Mongkut's Institute of Technology Ladkrabang, Bangkok, Thailand \\ Received 17 September 2021; received in revised form 18 November 2021; accepted 19 November 2021 \\ DOI: https://doi.org/10.46604/ijeti.2021.8499
}

\begin{abstract}
This study aims to design an electronically tunable voltage-mode (VM) universal filter utilizing commercially available LT1228 integrated circuits (ICs) with three-input and single-output (TISO) configuration. With the procedure based on two integrator loop filtering structures, the proposed filter consists of two LT1228s, four resistors, and two grounded capacitors. It realizes five filter output responses: low-pass, all-pass, band-reject, band-pass, and high-pass functions. By selecting input voltage signals, each output responses can be achieved without changing the circuit architecture. The natural angular frequency can be controlled electronically. The input voltage nodes $V_{i n 1}$ and $V_{i n 3}$ possess high impedance. The output node has low impedance, so it can be cascaded to other circuits. The performance of the proposed filter is corroborated by PSpice simulation and hardware implementation which support the theoretical assumptions. The result shows that the range of total harmonic distortion (THD) is lower than 1\%, and that the higher the temperature is, the lower the natural angular frequency is.
\end{abstract}

Keywords: universal filter, electronic controllability, LT1228, three-input and single-output

\section{Introduction}

Nowadays, many researchers give close attention to design multifunction or universal filters for providing various output responses without changing the circuit infrastructure. Among their proposed filters, the multiple-input single-output (MISO) multifunction filtering circuit using active building blocks (ABBs) is the most famous one. By switching on or off different input voltage signals, various output responses can be obtained. The advantages of ABBs include the compact structure and the cascade-able characteristic to other circuits. The circuits using the electronically controllable ABBs that are easily controlled by microcontrollers can make them essential for the use in modern analog circuits. Although ABBs are suitable for implementing circuit designs into an integrated circuit (IC) because of their small size, high circuit efficiency, low voltage, low power, etc., the process of implementing an IC into a chip is expensive. To lower the cost, some circuit designs use commercially available $\mathrm{ABBs}$ in specific applications because they are attractive and cheaper than other complementary metal oxide semiconductor (CMOS) or bipolar junction transistor (BJT) technology-based filters [1-7].

The realization of the analog biquad filter circuits using commercially available ABBs in specific applications has attracted great attention from researchers. The analog active filters using commercially available IC: LT1228 have been developed in electronic circuit designs for analog signal processing due to their advantageous features: cheapness, low total

* Corresponding author. E-mail address: 62603017@kmitl.ac.th 
harmonic distortion (THD), electronic control, fast transconductance amplifier, etc. The fast transconductance amplifier means

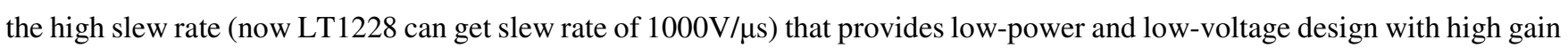
and high speed. Many research areas mainly focus on the analog active filters with these advantageous features, which are frequently used in the communication system, industrial electronic sensor technology, instrumentation, and control applications. LT1228 consists of an operational transconductance amplifier (OTA) that can convert the electric voltage ( $V$ ) into the electric current $(I)$ and a current feedback amplifier (CFA) that can amplify the OTA's output voltage. The CFA of LT1228 has high input impedance that offers an excellent buffer for its OTA. The LT1228 can actualize the gain control by varying the values of an external direct current (DC) bias current, $I_{B}$. Moreover, the LT1228 CFA can provide a wide range of voltage gain. As a result, it can be easily connected to other circuits. It can also drive low impedance loads like other CFAs with great linearity for high frequency applications [8].

In the open literature, many MISO universal biquadratic filters with ABBs have been reported [9-37]. Some simulations of CMOS or BJT technology-based filters are proposed only due to the expensive cost of implementing the circuits into chips $[12,17,19,22,24,36]$. Some ABBs requiring two or more commercially available ICs have been reported in previous studies [25-28, 30-35]. Other ABBs do not use grounded capacitors [16, 24-25, 28-30, 34, 37]. Moreover, some proposed filters do not have high input impedance [17, 19, 21, 24-25, 35]. Some proposed filters do not have low output impedance, so they do not require additional buffers at their output nodes [9-12, 16-21, 23, 28, 35-36]. Some proposed filters cannot conduct the electronic tuning for the natural angular frequency $\left(\omega_{0}\right)$ and the quality factor $(Q)$ [13-25]. Some filters cannot provide all five filtering responses: low-pass (LP), all-pass (AP), band-reject (BR), band-pass (BP), and high-pass (HP) functions [13, 14, 17, $21,25,35,36]$.

The focus of this work is to propose a three-input and single-output (TISO) voltage-mode (VM) universal filtering circuit using LT1228s. The proposed TISO filter design uses grounded capacitors, so it can reduce the parasitic impedance effects in LT1228 ICs. The electronic control of this design for $\omega_{0}$ and $Q$ can be conducted by a microcontroller or microcomputer, which is crucial for modernized analog circuits. The first input voltage $\left(V_{i n 1}\right)$ and the third input voltage $\left(V_{i n 3}\right)$ have high impedance. Also, the output voltage exhibits a low impedance level, so it can directly connect to other VM circuits without any buffer. The comparison of simulation and experimental results is described in this article to explore the accurate performance of the proposed TISO filter.

\section{Principle of Operation}

\subsection{Description of LT1228}

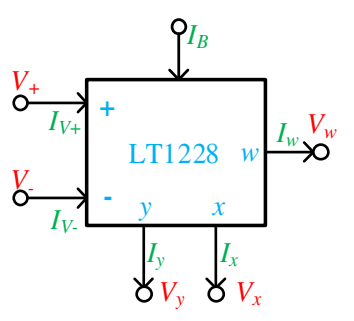

(a) Symbolic representation

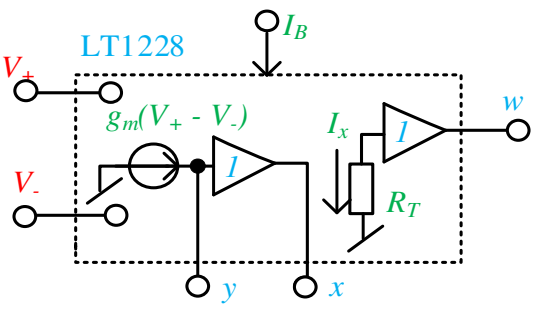

(b) Equivalent circuit

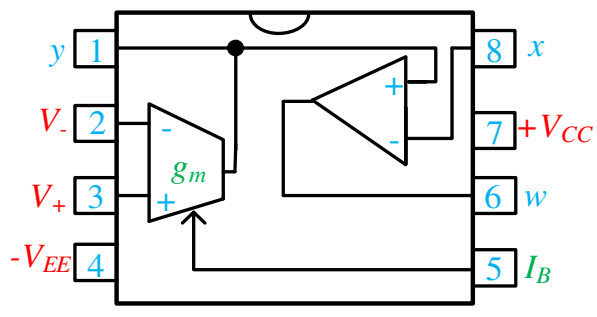

(c) Pin diagram

Fig. 1 LT1228

Fig. 1(a) describes the symbolic representation of LT1228 [8]. The $V_{+}, V_{-}$, and $y$ terminals of LT1228 have high impedance while the $x$ and $w$ terminals of LT1228 have low impedance. Figs. 1(b)-(c) represent the equivalent circuit and the pin diagram of LT1228, respectively [8]. The hybrid matrix form of LT1228 for the $V$-I relationship can be characterized as follows: 


$$
\left(\begin{array}{l}
I_{V+} \\
I_{V-} \\
I_{y} \\
V_{x} \\
V_{w}
\end{array}\right)=\left(\begin{array}{ccccc}
0 & 0 & 0 & 0 & 0 \\
0 & 0 & 0 & 0 & 0 \\
g_{m} & -g_{m} & 0 & 0 & 0 \\
0 & 0 & 1 & 0 & 0 \\
0 & 0 & 0 & R_{T} & 0
\end{array}\right)\left(\begin{array}{l}
V_{+} \\
V_{-} \\
V_{y} \\
I_{x} \\
I_{w}
\end{array}\right)
$$

where $R_{T}$ is the transresistance gain that has a very large value. The $R_{T}$ value is considered infinity as an ideal case. The value of small-signal $g_{m}$ in Eq. (1) can be controlled electronically by varying the bias currents $I_{B}$ of LT1228 as follows:

$$
g_{m}=I_{B} / 3.87 V_{T}
$$

where $I_{B}$ is the DC bias current, and $V_{T}$ is the thermal voltage.

\subsection{Synthesis block diagram of TISO VM universal filter}

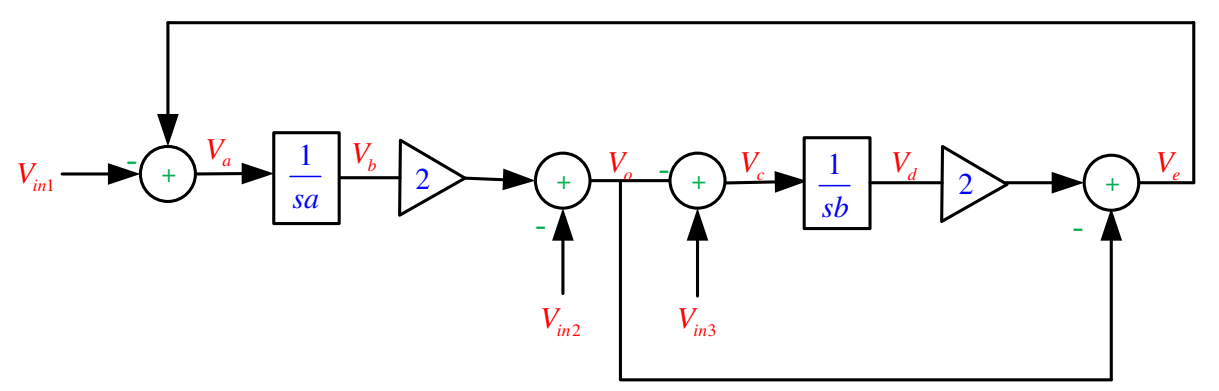

Fig. 2 Block diagram based on two lossless integrators of the proposed TISO VM universal filter

Fig. 2 illustrates the block diagram of the VM filter with TISO configuration. Eight basic blocks are used to synthesize the TISO filter: two lossless integrators, two voltage gain amplifiers, and four voltage summing circuits. The first summing block's input voltage nodes are $V_{i n 1}$ and $V_{e}$, and its output voltage node is $V_{a}$. The first lossless integrator's input voltage node is $V_{a}$, and its output voltage node $V_{b}$ is multiplied by the double voltage gain amplifier. The second summing block comprises double input voltage nodes: the $V_{\text {in } 2}$ node and the $V_{b}$ node multiplied by double voltage gain amplifier, and its output voltage node is $V_{o}$. The third summing block's input voltage nodes are $V_{i n 3}$ and $V_{o}$, and its output voltage node is $V_{c}$. The second lossless integrator's input voltage node is $V_{c}$, and its output voltage node $V_{d}$ is multiplied by the double voltage gain amplifier. The fourth summing block has dual input voltage nodes: the $V_{d}$ node multiplied by double voltage gain amplifier and the $V_{o}$ node, and its output voltage node is $V_{e} . a$ and $b$ represent the time constants of the two lossless integrator stages. The block diagram has three input voltage nodes $V_{i n 1}, V_{i n 2}$, and $V_{i n 3}$ with one voltage output node $V_{o}$.

$$
V_{o}=\frac{-s^{2} V_{i n 2}-\frac{2}{a} s V_{i n 1}+\frac{4}{a b} V_{i n 3}}{s^{2}+\frac{2}{a} s+\frac{4}{a b}}
$$

According to Eq. (3), a single output voltage node $V_{o}$ provides the following five filtering output responses.

(1) To get the LP function with unity passband voltage gain at the output node $V_{o}$, the input voltage signal must be applied at the $V_{i n 3}$ node, and the other nodes $V_{i n 1}$ and $V_{i n 2}$ must be grounded.

(2) To get the HP function with unity passband voltage gain at the output node $V_{o}$, the input voltage signal must be applied at the $V_{i n 2}$ node, and the other nodes $V_{i n 1}$ and $V_{i n 3}$ must be grounded.

(3) To get the BP function with unity passband voltage gain at the output node $V_{o}$, the input voltage signal must be applied at the $V_{i n 1}$ node, and the other nodes $V_{i n 2}$ and $V_{i n 3}$ must be grounded. 
(4) To get the BR function with unity passband voltage gain at the output node $V_{o}$, the inverting input must be applied at the $V_{i n 2}$ node, the non-inverting input voltage signal must be applied at the $V_{i n 3}$ node, and the $V_{i n 1}$ node must be grounded.

(5) To get the AP function with unity passband voltage gain at the output node $V_{o}$, the inverting input voltage signal must be applied at the $V_{i n 2}$ node, and the non-inverting input voltage signal must be applied at both $V_{i n 1}$ and $V_{i n 3}$ nodes.

Eq. (3) shows that the unity gain passband filter can be obtained for five filtering functions, and $\omega_{0}$ and $Q$ are respectively obtained as:

$$
\begin{aligned}
& \omega_{0}=\frac{2}{\sqrt{a b}} \\
& Q=\sqrt{\frac{a}{b}}
\end{aligned}
$$

Eq. (4) and (5) describe that $\omega_{0}$ can be controlled without affecting $Q$ by simultaneously adjusting the time constants ( $a$ and $b$ ) of the integrator circuits.

\subsection{TISO VM universal filter}

Fig. 3(a) illustrates the synthesis of the complete block diagram of the TISO VM universal filter using LT1228 as ABB [38]. It is composed of double voltage summing circuits and two lossless integrators. The synthesis configuration of the first lossless integrator is obtained by using the grounded capacitor $C_{1}$ and the first LT1228. Using the grounded capacitor $C_{2}$ and the second LT1228, the second lossless integrator can be obtained. To get the first voltage summing circuit, the first LT1228 and the resistors $R_{1}$ and $R_{2}$ are used. The second voltage summing circuit is also built utilizing the second LT1228 and the resistors $R_{3}$ and $R_{4}$. However, $V_{i n 2}$ is applied to series resistance $R_{2}$, so the input voltage nodes $V_{i n 1}$ and $V_{i n 3}$ have high impedance. The output voltage node $\left(V_{o}\right)$ is at $w$ terminal which provides ideally zero output impedance. Using this beneficial property, the proposed TISO universal filter can be directly connected to the external loads or input nodes of other VM circuits without using additional buffer devices. In practice, the output resistance $\left(Z_{o}\right)$ of the proposed filter is around $Z_{o} \cong R_{w l} / / R_{l}$ because the output resistance at $w$ terminal $\left(R_{w 1}\right)$ is not zero. The following output voltage equation of this proposed filter is expressed in Eq. (6).

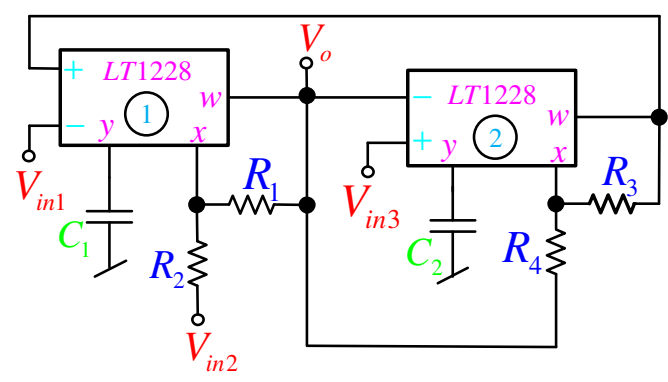

(a) Circuit diagram

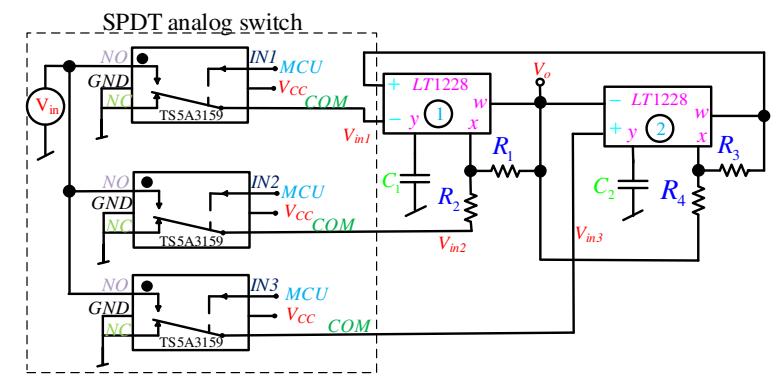

(b) With SPDT analog switch

Fig. 3 The proposed TISO VM biquad universal filter

According to Eq. (6), a single output voltage node that has low impedance provides five filtering output responses, as shown in Table 1. Number 1 denotes that the input voltage signal must be applied at that input node, number -1 denotes that the inverting input voltage signal must be applied at that input node, and number 0 denotes that the input node must be grounded.

$$
V_{0}=\frac{-s^{2} V_{i n 2}-\frac{2 g_{m 1}}{C_{1}} s V_{i n 1}+\frac{4 g_{m 1} g_{m 2}}{C_{1} C_{2}} V_{i n 3}}{s^{2}+\frac{2 g_{m 1}}{C_{1}} s+\frac{4 g_{m 1} g_{m 2}}{C_{1} C_{2}}}
$$


Table 1 Selection for each filtering response and filtering parameters

\begin{tabular}{|c|c|c|c|c|c|c|c|}
\hline \multicolumn{3}{|c|}{ Input } & \multirow{2}{*}{$\begin{array}{l}\text { Filtering } \\
\text { function }\end{array}$} & \multirow{2}{*}{ Transfer function } & \multirow{2}{*}{$\begin{array}{l}\text { Passband } \\
\text { gain }\end{array}$} & \multirow{2}{*}{ Natural angular frequency } & \multirow{2}{*}{ Quality factor } \\
\hline$V_{i n 1}$ & $V_{\text {in } 2}$ & $V_{i n 3}$ & & & & & \\
\hline 0 & 0 & 1 & $\begin{array}{l}\text { Low-pass } \\
\text { (LP) }\end{array}$ & $\frac{\frac{4 g_{m 1} g_{m 2}}{C_{1} C_{2}}}{s^{2}+\frac{2 g_{m 1}}{C_{1}} s+\frac{4 g_{m 1} g_{m 2}}{C_{1} C_{2}}}$ & 1 & \multirow{6}{*}{$\begin{array}{c}\omega_{0}=\sqrt{\frac{4 g_{m 1} g_{m 2}}{C_{1} C_{2}}} \\
\text { or } \\
\omega_{0}=\frac{2}{3.87 V_{T}} \sqrt{\frac{I_{B 1} I_{B 2}}{C_{1} C_{2}}}\end{array}$} & \multirow{6}{*}{$\begin{array}{l}Q=\sqrt{\frac{g_{m 2} C_{1}}{g_{m 1} C_{2}}} \\
Q=\sqrt{\frac{I_{B 2} C_{1}}{I_{B 1} C_{2}}}\end{array}$} \\
\hline 0 & 1 & 0 & $\begin{array}{l}\text { High-pass } \\
\text { (HP) }\end{array}$ & $\frac{-s^{2}}{s^{2}+\frac{2 g_{m 1}}{C_{1}} s+\frac{4 g_{m 1} g_{m 2}}{C_{1} C_{2}}}$ & -1 & & \\
\hline 1 & 0 & 0 & $\begin{array}{l}\text { Band-pass } \\
\text { (BP) }\end{array}$ & $\frac{-\frac{2 g_{m 1}}{C_{1}} s}{2 g_{m 1} \quad 4 g_{m 1} g_{m 2}}$ & -1 & & \\
\hline & & & & $s+\frac{C_{1}}{C_{1}} s+\frac{C_{1} C_{2}}{C_{1}}$ & & & \\
\hline 0 & -1 & 1 & $\begin{array}{l}\text { Band-reject } \\
\text { (BR) }\end{array}$ & $\frac{s^{2}+\frac{4 g_{m 1} g_{m 2}}{C_{1} C_{2}}}{s^{2}+\frac{2 g_{m 1}}{C_{1}} s+\frac{4 g_{m 1} g_{m 2}}{C_{1} C_{2}}}$ & 1 & & \\
\hline 1 & -1 & 1 & $\begin{array}{l}\text { All-pass } \\
\text { (AP) }\end{array}$ & $\frac{s^{2}-\frac{2 g_{m 1}}{C_{1}} s+\frac{4 g_{m 1} g_{m 2}}{C_{1} C_{2}}}{s^{2}+\frac{2 g_{m 1}}{C_{1}} s+\frac{4 g_{m 1} g_{m 2}}{C_{1} C_{2}}}$ & 1 & & \\
\hline
\end{tabular}

From Eq. (6), the five filtering output responses with unity passband voltage gain are provided. According to the above-mentioned description of $\omega_{0}$ and $Q$, the electronic tuning of the proposed circuit for $\omega_{0}$ is provided by varying the external DC bias currents value. To solve the input switching problem between the state when the input nodes are grounded and the state when the input nodes are used, the TS5A3159 analog switch is used, as shown in Fig. 3(b) [38]. This device is a single-pole double-throw (SPDT) analog switch with six pin configuration that only has one input terminal and two output terminals. When pin 6 (IN) is applied to a high signal (i.e., any digital output pin of microcontroller is connected to it), it provides pin $4(\mathrm{COM})$ connected to pin $1(\mathrm{NO})$. This means that pin 4 is applied to the related input voltage node of the proposed filter. Then, pin 5 is connected to $V_{C C}$ of the microcontroller. To complete the circuit when the switch is not pressed, the pulldown resistor is needed. This device is suitable for portable audio applications due to its excellent THD performance and very low power consumption [39].

\section{Parasitic Effects of LT1228}

The parasitic effects of LT1228 deviate the performance of the proposed TISO filter. The $V_{+}, V_{-}$, and $y$ terminal have high impedance so that the parasitic components $R$ and $C$ are paralleled, named as $R_{+}, C_{+}, R_{-}, C_{-}, R_{y}$, and $C_{y}$, respectively. The $x$ and $w$ terminals with low impedance show up in the arrangement resistors $R_{x}$ and $R_{w}$, individually. The important transresistance gain $R_{T}$ is described as parallel to $R_{T}$ and $C_{T}$, which are most effective on the circuit function. In the summing circuits, LT1228's datasheet states that the value of the resistors $\left(R_{1}\right.$ and $\left.R_{3}\right)$ providing feedback from $w$ to $x$ terminal should be low [8]. As a result, $C_{T}$ and $R_{T}$ effect can be reduced, and a wider range of operating frequency can be achieved. Besides, if the passband frequency range of the TISO filter is expected below $10 \mathrm{MHz}$, there will be only parasitic effects from $R_{-}, C_{-}, R_{y}, C_{y}, R_{+}$, and $C_{+}$ terminals (the parasitic effect from $R_{x}, R_{w}, R_{T}$, and $C_{T}$ terminals are ignored). With these parasitic effects of LT1228, the output voltage equation of this TISO filter in Fig. 3(a) is as follows: 


$$
\begin{aligned}
& V_{o}^{*}=\frac{\left[s^{2}+s\left(\frac{G_{y 1} C_{2}^{*}+G_{y 2} C_{1}^{*}}{C_{1}^{*} C_{2}^{*}}\right)+\frac{G_{y 1} G_{y 2}}{C_{1}^{*} C_{2}^{*}}\right] V_{i n 2}+\left[\frac{2 g_{m 1}\left(G_{y 2}+s C_{2}^{*}\right)}{C_{1}^{*} C_{2}^{*}}\right] V_{i n 1}+\frac{4 g_{m 1} g_{m 2}}{C_{1}^{*} C_{2}^{*}} V_{i n 3}}{D^{*}(s)} \\
& D^{*}(s)=s^{2}+\left(\frac{G_{y 1} C_{2}^{*}+G_{y 2} C_{1}^{*}+2 g_{m 1} C_{2}^{*}}{C_{1}^{*} C_{2}^{*}}\right) s+\frac{G_{y 1} G_{y 2}+4 g_{m 1} g_{m 2}+2 g_{m 1} G_{y 2}}{C_{1}^{*} C_{2}^{*}}
\end{aligned}
$$

where

$$
\begin{aligned}
& C_{1}^{*}=C_{1}+C_{y 1} \\
& C_{2}^{*}=C_{2}+C_{y 2} \\
& G_{y 1}=\frac{1}{R_{y 1}} \\
& G_{y 2}=\frac{1}{R_{y 2}}
\end{aligned}
$$

According to Eq. (7), the natural angular frequency and the quality factor with parasitic elements are as follows:

$$
\begin{aligned}
& \omega_{0}^{*}=\sqrt{\frac{G_{y 1} G_{y 2}+4 g_{m 1} g_{m 2}+2 g_{m 2} G_{y 1}}{C_{1}^{*} C_{2}^{*}}} \\
& Q^{*}=\frac{1}{\frac{G_{y 1}}{C_{1}^{*}}+\frac{G_{y 2}^{*}}{C_{2}^{*}}+\frac{2 g_{m 2}}{C_{2}^{*}}} \sqrt{\frac{G_{y 1} G_{y 2}^{*}+4 g_{m 1} g_{m 2}+2 g_{m 2} G_{y 1}}{C_{1}^{*} C_{2}^{*}}}
\end{aligned}
$$

According to Eqs. (7), (8), (13), and (14), the non-ideal LT1228 affects the performance of the TISO filter response, such as the operational frequency, passband voltage gain, natural angular frequency, and quality factor.

\section{Simulation Results}

The proposed filter has been simulated with PSpice simulation. The LT1228's macro model is utilized. According to the LT1228 datasheet with $I_{B}=100 \mu \mathrm{A}$, the LT1228 parasitic elements are obtained as $R_{+}=R_{-}=200 \mathrm{k} \Omega, C_{+}=C_{-}=3 \mathrm{pF}, R_{y}=8$ $\mathrm{M} \Omega$, and $C_{y}=6 \mathrm{pF} . R_{T}=197.66 \mathrm{k} \Omega, C_{T}=5.95 \mathrm{pF}, r_{x}=46.92 \Omega$, and $r_{w}=19.80 \Omega$ are obtained from simulation. The power supply voltages of the proposed filter are $\pm 5 \mathrm{~V}$. The component values used in this filtering circuit are expressed as the following. $1 \mathrm{k} \Omega$ is chosen for all resistors $\left(R_{1}, R_{2}, R_{3}\right.$, and $\left.R_{4}\right), 2.7 \mathrm{nF}$ is selected for two capacitors $\left(C_{1}\right.$ and $\left.C_{2}\right)$, and $123.6 \mu \mathrm{A}$ is used for all external bias currents $\left(I_{B 1}\right.$ and $\left.I_{B 2}\right)$.

From Table $1, f_{0}$ and $Q$ are achieved as $145.72 \mathrm{kHz}$ and 1 , respectively. The magnitude of the four filtering output responses (LP, HP, BP, and BR) versus the frequency of the TISO filter is shown in Fig. 4. The simulated quality factor $Q=$ 0.98 and the natural angular frequency $f_{0}=143.55 \mathrm{kHz}$ can be verified in this figure. The percent deviation of the expected and simulated value of $Q$ and $f_{0}$ is $2 \%$ and $1.4 \%$. To obtain the gain $=0 \mathrm{~dB}$ and $f_{0}=143.55 \mathrm{kHz}$ for AP function, the bias currents are set to $123.6 \mu \mathrm{A}$, and the values of all resistors are set to $1 \mathrm{k} \Omega$. The magnitude response and phase angle of AP filter function are illustrated in Fig. 5. To control the $f_{0}$ value without disturbing $Q, I_{B 1}$ and $I_{B 2}$ are simultaneously adjusted to $70 \mu \mathrm{A}$, $140 \mu \mathrm{A}$, and $210 \mu \mathrm{A}$. Using a microcontroller, the variation of bias currents will be easily obtained. With these above values of DC bias current and $Q=0.98$, different values of $f_{0}$ are plotted at $81.66 \mathrm{kHz}, 155.95 \mathrm{kHz}$, and $243.78 \mathrm{kHz}$, respectively. 
Fig. 6 verifies that $f_{0}$ can be linearly and electronically controlled without affecting $Q$. The simulated BP frequency response with four different temperature values is shown in Fig. 7. According to Table $1, f_{0}$ has an inverse relationship with $V_{T}$, so the higher the temperature value is, the lower the $f_{0}$ is. Fig. 8 presents the simulated LP, HP, BP, and AP functions of THD values versus the amplitude of the input voltage, where the sinusoidal input voltage ranges from $1 \mathrm{mV}_{\mathrm{P}}$ to $100 \mathrm{mV}_{\mathrm{P}}$. The proposed TISO filter is designed to have $f_{0}=143.55 \mathrm{kHz}$. It can be verified that the range of THD values is adjusted from $0.018 \%$ to $9.5236 \%$, and that the value of all functions (LP, HP, BP, and AP) is not above $1 \%$ below $40 \mathrm{mV}_{\mathrm{P}}$ of the sinusoidal input voltage signal. The BR function of the TISO filter for THD values is shown in Fig. 9, where the low and high passband frequencies are respectively located at $10 \mathrm{kHz}$ and $1 \mathrm{MHz}$. The range of THD values is varied from $0.02 \%$ to $0.15 \%$, and the value for $10 \mathrm{kHz}$ is not over $1 \%$ at the amplitude of the input voltage below $40 \mathrm{mV}_{\mathrm{P}}$.

Figs. 4-9 show that the simulation results of the proposed filter operate under the theoretical facts. It is obvious that the LT1228 parasitic elements (especially $R_{T}$ ) as analyzed in section 3 noticeably affect the performance of the proposed filter at high frequency. According to the experiment, this effect also appears from the wiring and breadboard. The simulated output impedance $Z_{o}$ is around $60.12 \Omega$. The simulated frequency band of this filter is about $10 \mathrm{MHz}$. The range of THD value is lower than $1 \%$ when the applied amplitude of the sine wave input signal is lower than $40 \mathrm{mV}_{\mathrm{p}}$.

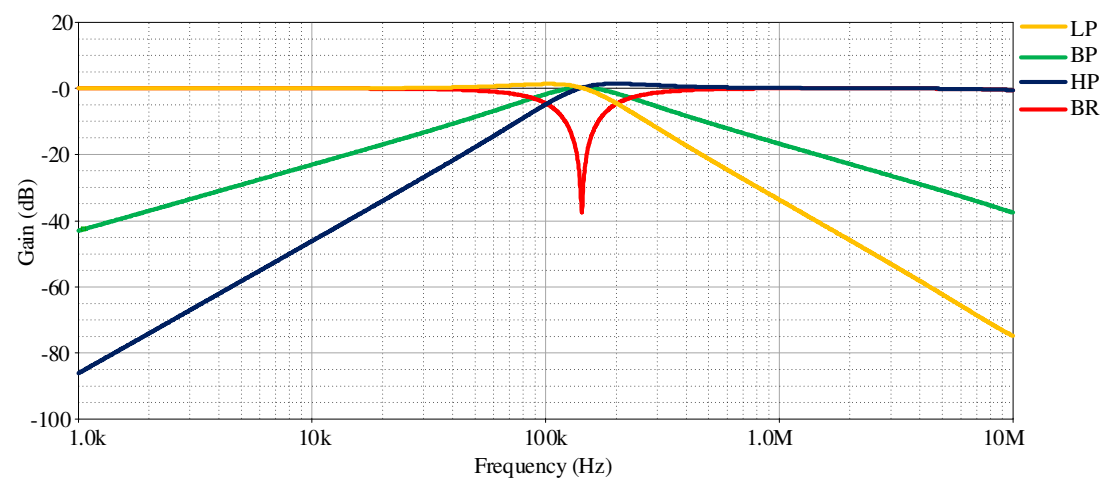

Fig. 4 Simulated magnitude response of TISO filter

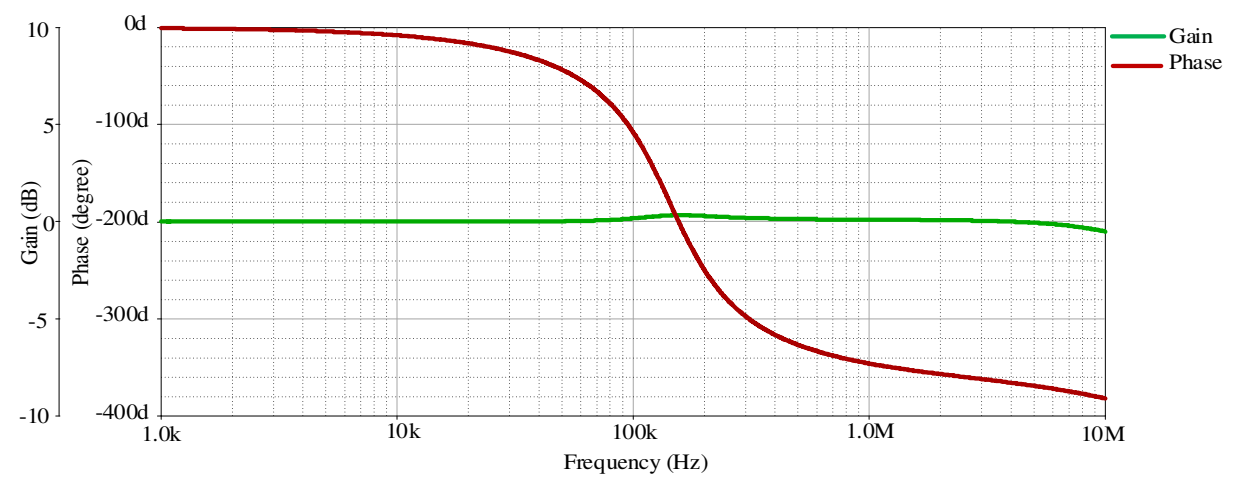

Fig. 5 Simulated magnitude and phase response of AP filter function

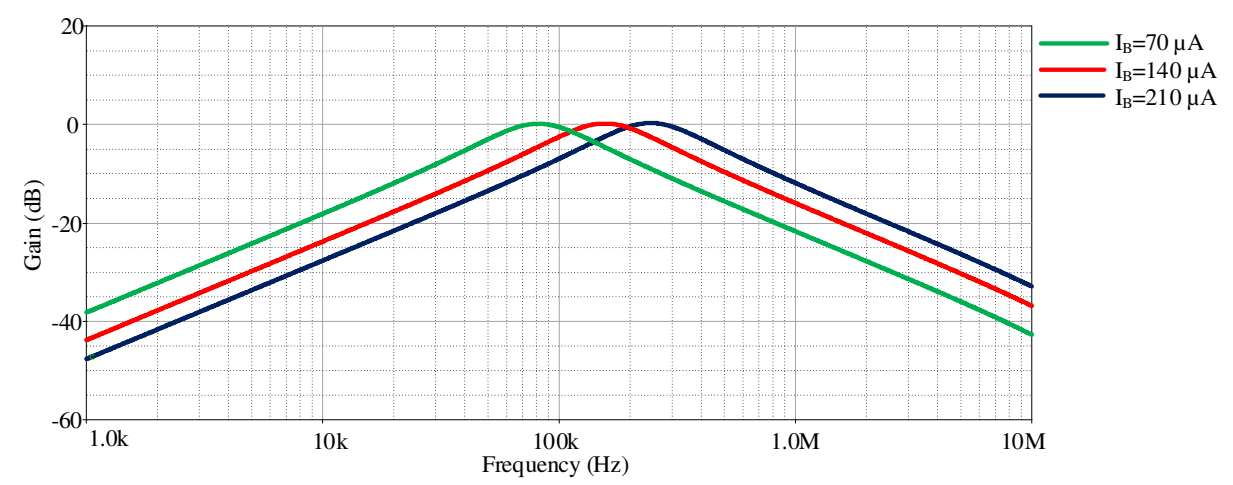

Fig. 6 Simulated BP frequency response with different values of $I_{B}$ at $Q=0.97$ 


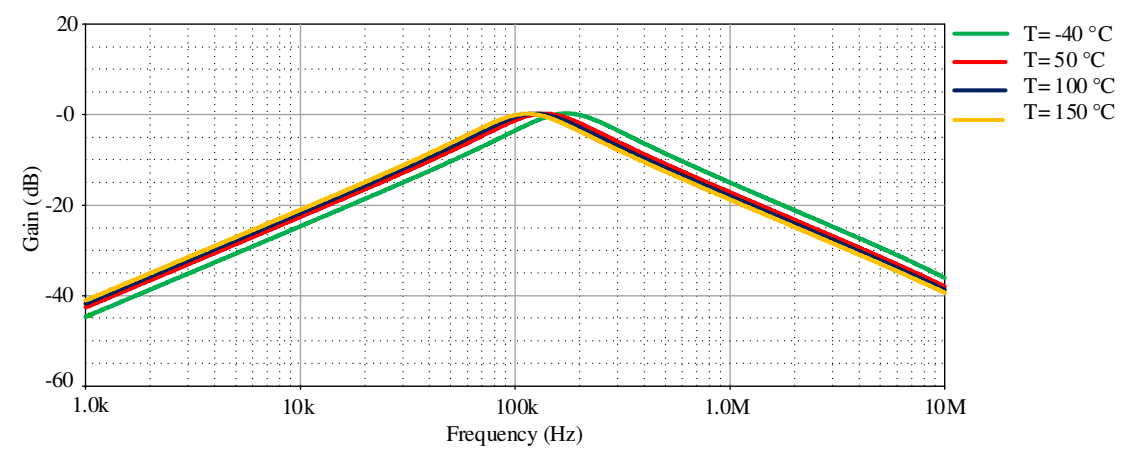

Fig. 7 Simulated BP frequency response with four different temperature values

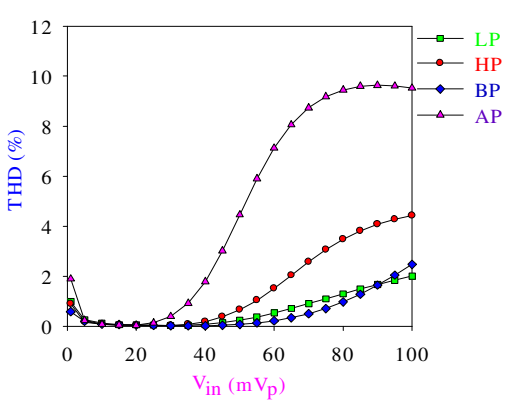

Fig. 8 THD values versus input voltage amplitude under four filtering functions

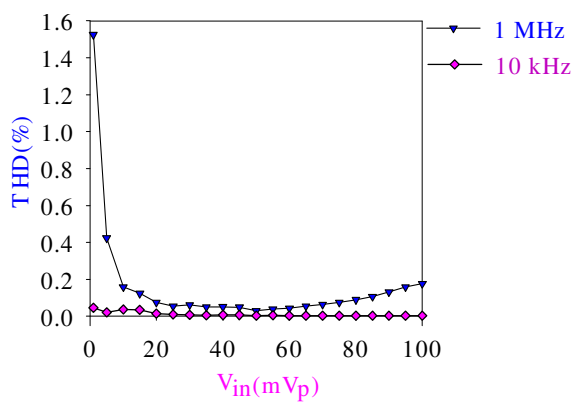

Fig. 9 THD values versus input voltage amplitude under BR function (where $f=10 \mathrm{kHz}$ and $1 \mathrm{MHz}$ )

\section{Experimental Results}

The proposed universal filter is experimentally tested by using two LT1228s. This circuit uses GW Instek GPS-3303 power supply for supplying $\pm 5 \mathrm{~V}$. The voltage measurement of the sine wave input signal and the resultant output waveforms are obtained via Keysight DSOX1102G oscilloscope. The experimental setup is illustrated in Fig. 10. The external DC bias currents and passive component values for this circuit are set as $I_{B 1}=I_{B 2}=123.6 \mu \mathrm{A}, C_{1}=C_{2}=2.7 \mathrm{n} \mathrm{F}$, and $R_{1}=R_{2}=R_{3}=R_{4}=$ $1 \mathrm{k} \Omega$. The natural angular frequency and the quality factor are analyzed by using the mentioned component values in Table 1 , providing $f_{0}=145.72 \mathrm{kHz}$ and $Q=1$.

Fig. 11 shows the LP, BP, HP, and BR filtering responses of the TISO filter for the measured experimental magnitude response. To maintain the linear operating region of LT1228, the proposed filter uses the input voltage amplitude $50 \mathrm{mV}_{\mathrm{p}-\mathrm{p}}$. The experimental natural angular frequency of the proposed TISO filter is approximately $144 \mathrm{kHz}$, so the percent deviation of calculated and experimental values of $f_{0}$ is about $1.2 \%$. The experimental magnitude response and phase angle of AP are demonstrated in Fig. 12. This figure verifies that the phase angle of the TISO filter is shifted between 0 and 360. To investigate the measured input signal and the resultant output waveforms of the BP filtering response for the TISO universal filter, a sine wave input signal with a peak-to-peak voltage value of $50 \mathrm{mV}_{\mathrm{p}-\mathrm{p}}$ is applied (@ $50 \mathrm{kHz}, 144 \mathrm{kHz}$, and $500 \mathrm{kHz}$ ). It is proved that the amplitude of the output voltages is attenuated at low $(50 \mathrm{kHz})$ and high frequency $(500 \mathrm{kHz})$ while the amplitude of the input and output voltages are the same at the natural angular frequency $(144 \mathrm{kHz})$ in Fig. 13.

The tuning of the natural angular frequency with the constant kept at $Q=0.98$ is tested. In this experiment, three different bias currents $I_{B 1}=I_{B 2}=I_{B}$ are assigned to $70 \mu \mathrm{A}, 140 \mu \mathrm{A}$, and $210 \mu \mathrm{A}$. The result of the experimented natural angular frequency with these bias currents is shown in Fig. 14. The experimented natural angular frequency is located at $82.6 \mathrm{kHz}, 163.5 \mathrm{kHz}$, and $246.8 \mathrm{kHz}$, respectively. By using a microcontroller, the varying value of $I_{B 1}$ and $I_{B 2}$ is easily done in practical work. The AP transient response of the proposed TISO universal filter can be investigated in Fig. 15, where a sinusoidal wave with a peak-to-peak voltage value $50 \mathrm{mV}_{\mathrm{p}-\mathrm{p}} @ 50 \mathrm{kHz}, 140 \mathrm{kHz}$, and $500 \mathrm{kHz}$ is applied to the input of this filter. It is verified that the amplitude of the input and output voltages are the same at the above-mentioned three different frequencies. The comparison between the filter design proposed in previous studies and the one proposed in this present study is shown in Table 2. 


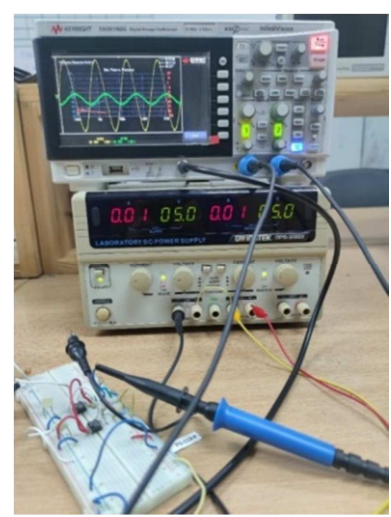

Fig. 10 Experimental setup

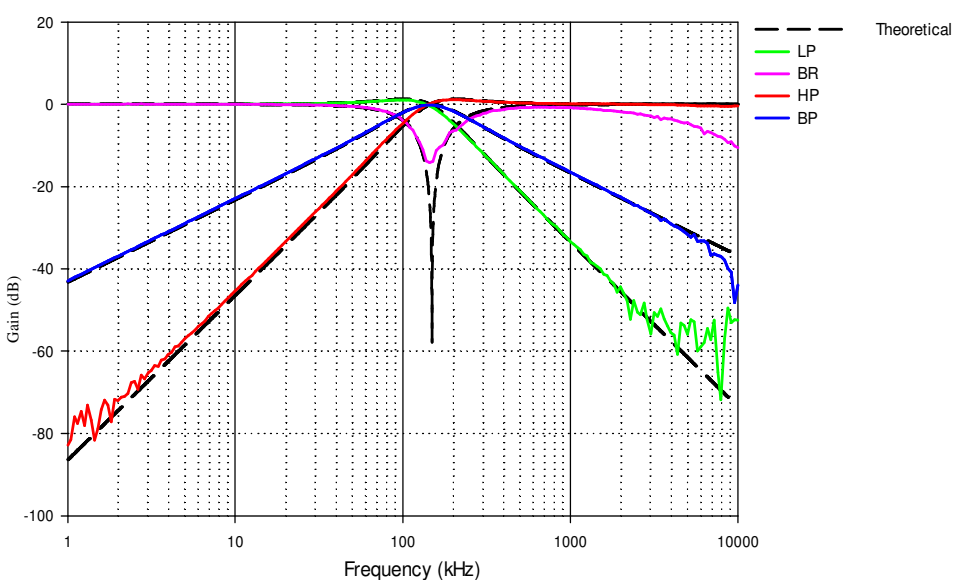

Fig. 11 Experimental gain response of TISO filtering circuit

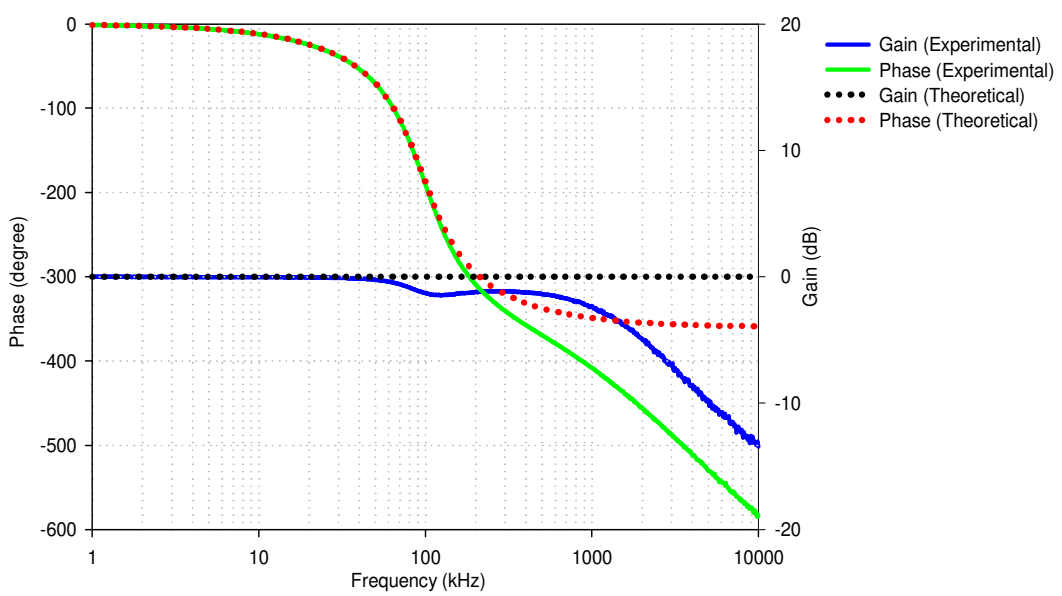

Fig. 12 Experimental gain response and phase angle of TISO AP filtering circuit

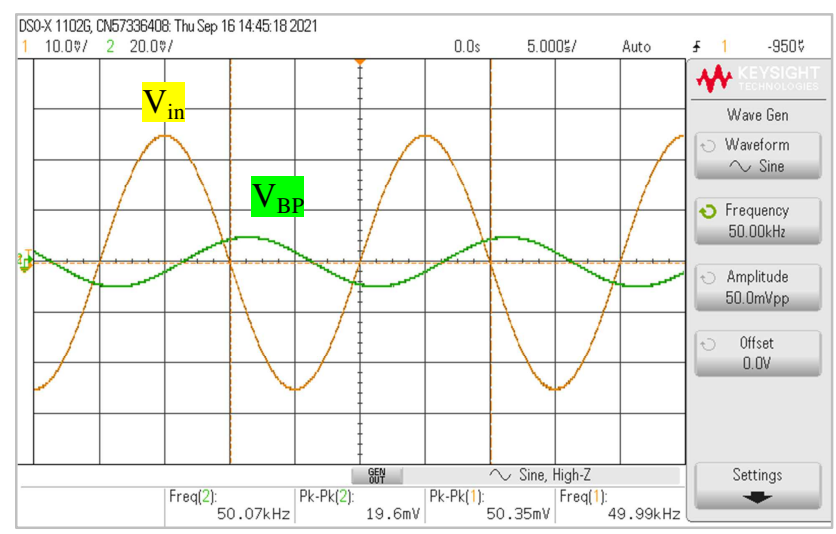

(a) $f=50 \mathrm{kHz}$

Fig. 13 Measured BP transient response of TISO universal filtering circuit 


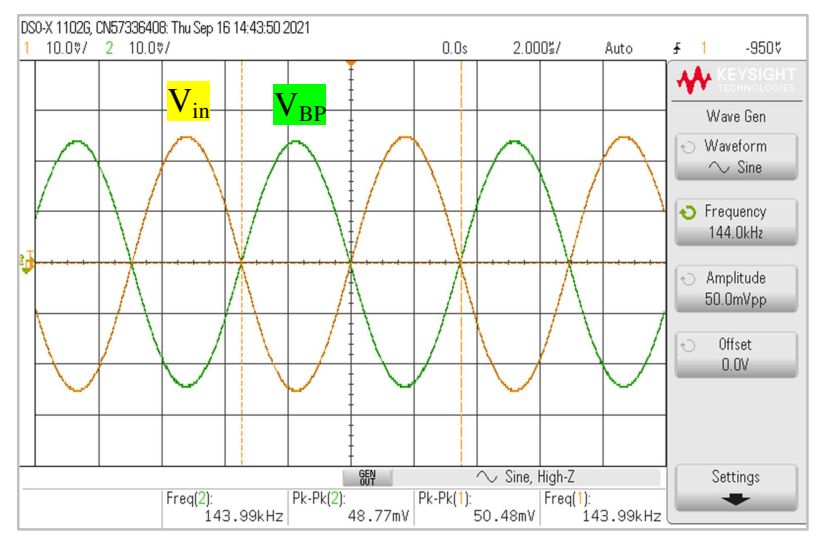

(b) $f=144 \mathrm{kHz}$

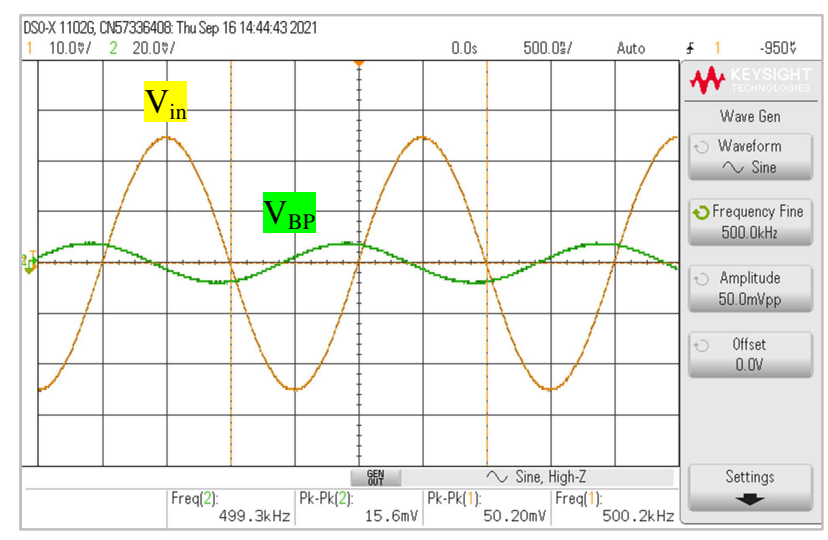

(c) $f=500 \mathrm{kHz}$

Fig. 13 Measured BP transient response of TISO universal filtering circuit (continued)

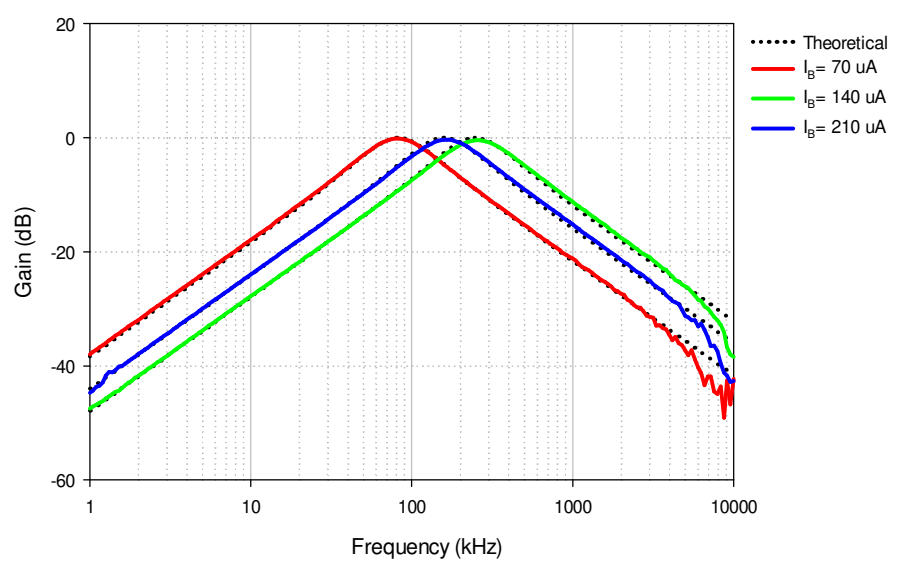

Fig. 14 Experimental BP function of TISO filter with three different $I_{B}$ values

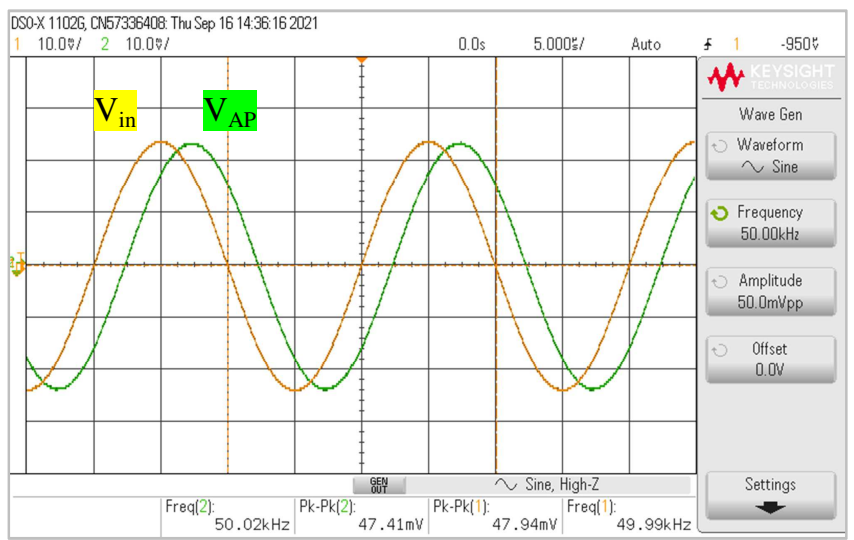

(a) $f=50 \mathrm{kHz}$

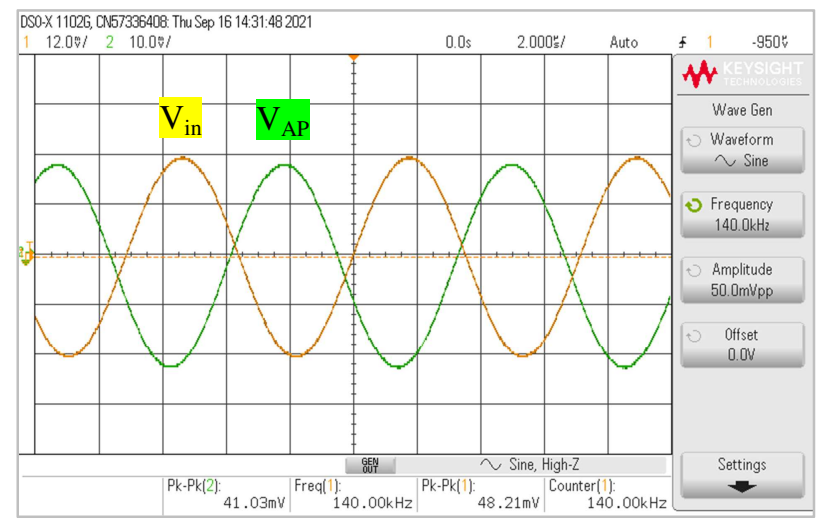

(b) $f=140 \mathrm{kHz}$

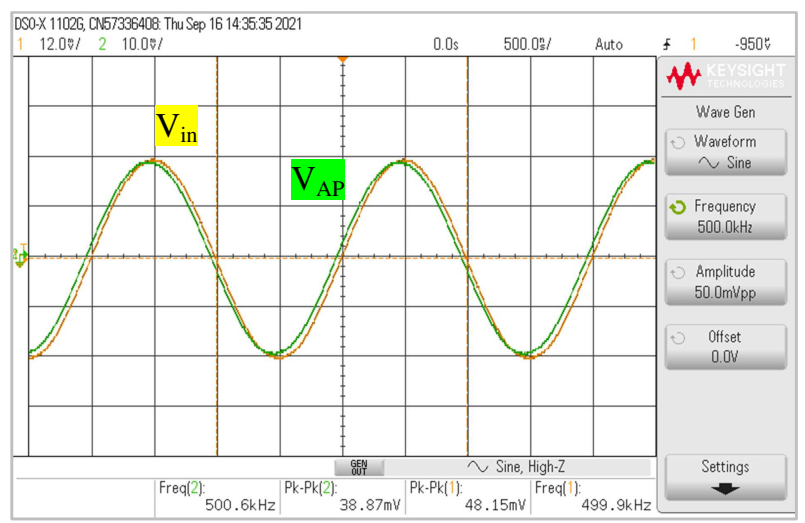

(c) $f=500 \mathrm{kHz}$

Fig. 15 Measured AP transient response of TISO universal filter 
Table 2 Comparison between the proposed design using LT1228s and other VM filters with different ABBs

\begin{tabular}{|c|c|c|c|c|c|c|c|c|c|c|c|c|}
\hline Ref. & $\mathrm{ABB}$ & $\begin{array}{c}\text { No. } \\
\text { of } \\
\text { ABBs }\end{array}$ & $\begin{array}{l}\text { No. of } \\
\text { commercial } \\
\text { ICs }\end{array}$ & $\begin{array}{l}\text { Filtering } \\
\text { category }\end{array}$ & $\begin{array}{l}\text { Grounded } \\
\text { capacitors }\end{array}$ & $\begin{array}{c}\text { Low } \\
\text { output } \\
\text { impedance }\end{array}$ & $\begin{array}{c}\text { High } \\
\text { input } \\
\text { impedance }\end{array}$ & $\begin{array}{c}\text { Supply } \\
\text { voltage, } \\
\text { power } \\
\text { consumption }\end{array}$ & $\begin{array}{c}\text { Natural } \\
\text { angular } \\
\text { frequency, } \\
f_{o}(\mathrm{~Hz})\end{array}$ & $\begin{array}{l}\text { Electronic } \\
\text { tune of } \omega_{0}\end{array}$ & $\begin{array}{l}\text { Filtering } \\
\text { responses }\end{array}$ & $\begin{array}{l}\text { Sim. } \\
\text { /Exp. }\end{array}$ \\
\hline [9] & OTA & 5 & 5 & MIMO & Yes & No & Yes & $\begin{array}{c} \pm 15 \mathrm{~V} \\
114-861 \mathrm{~mW}\end{array}$ & $159.16 \mathrm{k}$ & Yes & $\begin{array}{l}\mathrm{LP}, \mathrm{HP}, \mathrm{BP}, \\
\mathrm{BR} \text {, and AP }\end{array}$ & Both \\
\hline [10] & OTA & 6 & 6 & MISO & Yes & No & Yes & $\pm 5 \mathrm{~V}, \mathrm{NA}$ & $31 \mathrm{k}$ & Yes & $\begin{array}{l}\mathrm{LP}, \mathrm{HP}, \mathrm{BP}, \\
\mathrm{BR} \text {, and AP }\end{array}$ & Both \\
\hline [11] & OTA & 8 & 8 & SIMO & Yes & No & Yes & $\pm 5 \mathrm{~V}, \mathrm{NA}$ & $30.55 \mathrm{k}$ & Yes & $\begin{array}{l}\mathrm{LP}, \mathrm{HP}, \mathrm{BP}, \\
\mathrm{BR} \text {, and AP }\end{array}$ & Both \\
\hline [12] & OTA & 6 & - & SIMO & Yes & No & Yes & NA & $1.5 \mathrm{M} * *$ & Yes & $\begin{array}{l}\mathrm{LP}, \mathrm{HP}, \mathrm{BP}, \\
\mathrm{BR} \text {, and AP }\end{array}$ & Sim. \\
\hline [13] & AD844 & 3 & 3 & MIMO & Yes & Yes & Yes & $\begin{array}{c} \pm 6 \mathrm{~V} \\
168 \mathrm{~mW}\end{array}$ & $117.9 \mathrm{k}$ & No & HP, BP, and LP & Both \\
\hline [14] & AD844 & 3 & 3 & SIMO & Yes & Yes & Yes & $\begin{array}{c} \pm 6 \mathrm{~V} \\
168 \mathrm{~mW}\end{array}$ & $102 \mathrm{k}$ & No & $\begin{array}{l}\text { LP, BP, and } \\
\text { BR }\end{array}$ & Both \\
\hline [15] & AD844 & 3 & 3 & MIMO & Yes & Yes & Yes & $\begin{array}{c} \pm 6 \mathrm{~V} \\
180 \mathrm{~mW}\end{array}$ & $39.79 \mathrm{k}$ & No & $\begin{array}{c}\mathrm{LP}, \mathrm{HP}, \mathrm{BP}, \\
\text { and BR }\end{array}$ & Both \\
\hline [16] & CCII & 2 & 3 & MISO & No & No & Node $V_{i n 3}$ & $\pm 6 \mathrm{~V}, \mathrm{NA}$ & $72.34 \mathrm{k}$ & No & $\begin{array}{l}\mathrm{LP}, \mathrm{HP}, \mathrm{BP}, \\
\mathrm{BR} \text {, and AP }\end{array}$ & Both \\
\hline [17] & CCII & 4 & - & SIMO & Yes & No & No & NA & NA & No & LP, HP, and BP & Sim. \\
\hline$[18]$ & CCII & 4 & 4 & SIMO & Yes & No & Yes & $\pm 15 \mathrm{~V}, \mathrm{NA}$ & $16 \mathrm{k}$ & No & $\begin{array}{l}\text { LP, HP, BP, } \\
\text { BR, and AP }\end{array}$ & Both \\
\hline [19] & DVCC & 2 & - & SIMO & Yes & No & No & NA & $795.75 \mathrm{k} * *$ & No & $\begin{array}{l}\mathrm{LP}, \mathrm{HP}, \mathrm{BP}, \\
\mathrm{BR} \text {, and AP }\end{array}$ & Sim. \\
\hline \multirow{2}{*}{ [20] } & DDCC & 3 & 3 & MISO & Yes & No & $\begin{array}{c}\text { Nodes } \\
V_{i n 1}, V_{i n 2}, \\
V_{i n 3}, V_{i n 4}, \\
\text { and } V_{i n 6}\end{array}$ & $\pm 15 \mathrm{~V}, \mathrm{NA}$ & $159.155 \mathrm{k}$ & No & $\begin{array}{l}\mathrm{LP}, \mathrm{HP}, \mathrm{BP}, \\
\mathrm{BR} \text {, and AP }\end{array}$ & Both \\
\hline & DDCC & 3 & 3 & SIMO & Yes & No & $\begin{array}{c}\text { Nodes } \\
V_{i n 1}, V_{i n 2}, \\
V_{i n 3}, V_{i n 4}, \\
\text { and } V_{i n 6}\end{array}$ & $\pm 15 \mathrm{~V}, \mathrm{NA}$ & $159.155 \mathrm{k}$ & No & $\begin{array}{l}\mathrm{LP}, \mathrm{HP}, \mathrm{BP}, \\
\mathrm{BR} \text {, and AP }\end{array}$ & Both \\
\hline [21] & $\begin{array}{c}\text { DDCC } \\
\text { (Fig. } 4 \text { (b)) }\end{array}$ & 4 & - & SIMO & Yes & No & No & NA & 864 & No & $\mathrm{LP}, \mathrm{HP}$, and BP & Both \\
\hline [22] & DDCC & 3 & - & SIMO & Yes & $\begin{array}{c}\text { Nodes BR } \\
\text { and AP }\end{array}$ & Yes & NA & $3.18 \mathrm{M} * *$ & No & $\begin{array}{l}\mathrm{LP}, \mathrm{BP}, \mathrm{HP}, \\
\mathrm{BR} \text {, and AP }\end{array}$ & Sim. \\
\hline \multirow{2}{*}{ [23] } & FDCCIIDDCC & $\begin{array}{l}1 \\
1\end{array}$ & $\begin{array}{l}1 \\
1\end{array}$ & SIMO & Yes & No & $\begin{array}{c}\text { Nodes } \\
V_{\text {in } 2}, V_{i n 4}, \\
\text { and } V_{i n 5}\end{array}$ & $\pm 15 \mathrm{~V}, \mathrm{NA}$ & $159.155 \mathrm{k}$ & No & $\begin{array}{l}\mathrm{LP}, \mathrm{HP}, \mathrm{BP} \text {, } \\
\mathrm{BR} \text {, and AP }\end{array}$ & Both \\
\hline & FDCCIIDDCC & $\begin{array}{l}1 \\
1\end{array}$ & $\begin{array}{l}1 \\
1\end{array}$ & MISO & Yes & No & $\begin{array}{c}\text { Nodes } \\
V_{i n 2}, V_{i n 4}, \\
\text { and } V_{i n 5} \\
\end{array}$ & $\pm 15 \mathrm{~V}, \mathrm{NA}$ & $159.155 \mathrm{k}$ & No & $\begin{array}{l}\mathrm{LP}, \mathrm{HP}, \mathrm{BP}, \\
\mathrm{BR} \text {, and AP }\end{array}$ & Both \\
\hline [24] & CDBA & 2 & - & MISO & No & Yes & No & NA & NA & No & $\begin{array}{l}\mathrm{LP}, \mathrm{HP}, \mathrm{BP}, \\
\mathrm{BR} \text {, and AP }\end{array}$ & Sim. \\
\hline [25] & CDBA & 1 & 3 & SIMO & No & Yes & No & $\pm 5 \mathrm{~V}, \mathrm{NA}$ & NA & No & LP, HP, and BP & Both \\
\hline \multirow{2}{*}{ [26] } & VD-DIBA & 2 & 4 & MIMO & Yes & $\begin{array}{l}\text { Nodes } V_{o 1} \\
\text { and } V_{o 3}\end{array}$ & Yes & $\pm 5 \mathrm{~V}, \mathrm{NA}$ & $100 \mathrm{k}$ & Yes & $\begin{array}{l}\mathrm{LP}, \mathrm{HP}, \mathrm{BP}, \\
\mathrm{BR} \text {, and AP }\end{array}$ & Both \\
\hline & VD-DIBA & 2 & 4 & SIMO & Yes & $\begin{array}{c}\text { Nodes HP } \\
\text { and BR }\end{array}$ & Yes & $\pm 5 \mathrm{~V}, \mathrm{NA}$ & $100 \mathrm{k}$ & Yes & $\begin{array}{c}\mathrm{LP}, \mathrm{BP}, \mathrm{HP} \\
\text { and BR }\end{array}$ & Both \\
\hline [27] & VD-DIBA & 2 & 4 & MISO & Yes & Yes & Yes & $\pm 5 \mathrm{~V}, \mathrm{NA}$ & $350 \mathrm{k}$ & Yes & $\begin{array}{l}\mathrm{LP}, \mathrm{HP}, \mathrm{BP}, \\
\mathrm{BR} \text {, and AP }\end{array}$ & Both \\
\hline [28] & VDCC & 1 & 4 & MISO & No & No & Node $V_{i n 5}$ & $\pm 5 \mathrm{~V}, \mathrm{NA}$ & $2.05 \mathrm{M}$ & Yes & $\begin{array}{l}\mathrm{LP}, \mathrm{HP}, \mathrm{BP}, \\
\mathrm{BR} \text {, and AP }\end{array}$ & Both \\
\hline [29] & VDBA & 2 & 2 & MISO & No & Yes & $\begin{array}{c}\text { Nodes } V_{i n 1} \\
\text { and } V_{i n 3}\end{array}$ & $\pm 5 \mathrm{~V}, \mathrm{NA}$ & $1.59 \mathrm{M}$ & Yes & $\begin{array}{l}\text { LP, HP, BP, } \\
\text { BR, and AP }\end{array}$ & Both \\
\hline [30] & VDBA & 2 & 4 & MISO & No & Yes & Yes & $\pm 5 \mathrm{~V}, \mathrm{NA}$ & $50 \mathrm{k}$ & Yes & $\begin{array}{l}\mathrm{LP}, \mathrm{HP}, \mathrm{BP}, \\
\mathrm{BR} \text {, and AP }\end{array}$ & Exp. \\
\hline [31] & VDDDA & 2 & 4 & MISO & Yes & Yes & Yes & $\pm 5 \mathrm{~V}, \mathrm{NA}$ & $49 \mathrm{k}$ & Yes & $\begin{array}{l}\text { LP, HP, BP, } \\
\text { BR, AP }\end{array}$ & Both \\
\hline [32] & VDDDA & 2 & 4 & MISO & Yes & Yes & Yes & $\pm 5 \mathrm{~V}, \mathrm{NA}$ & $180 \mathrm{k}$ & Yes & $\begin{array}{l}\mathrm{LP}, \mathrm{HP}, \mathrm{BP}, \\
\mathrm{BR} \text {, and AP }\end{array}$ & Both \\
\hline [33] & VDDDA & 3 & 6 & SIMO & Yes & $\begin{array}{c}\text { Nodes HP } \\
\text { and AP }\end{array}$ & Yes & $\pm 5 \mathrm{~V}, \mathrm{NA}$ & $123 \mathrm{k}$ & Yes & $\begin{array}{l}\mathrm{LP}, \mathrm{BP}, \mathrm{HP}, \\
\mathrm{BR} \text {, and AP }\end{array}$ & Both \\
\hline [34] & EX-CCCII & 1 & 5 & MISO & No & Yes & No & $\pm 8 \mathrm{~V}, \mathrm{NA}$ & $722 \mathrm{k}$ & Yes & $\begin{array}{l}\mathrm{LP}, \mathrm{HP}, \mathrm{BP}, \\
\mathrm{BR} \text {, and AP }\end{array}$ & Both \\
\hline \multirow{3}{*}{ [35] } & DDCCTA & 1 & 3 & MIMO & Yes & No & Yes & $\pm 5 \mathrm{~V}, \mathrm{NA}$ & $1.061 \mathrm{M}$ & Yes & LP, BP, and HP & Both \\
\hline & DDCCTA & 1 & 3 & MIMO & Yes & No & No & $\pm 5 \mathrm{~V}, \mathrm{NA}$ & $1.061 \mathrm{M}$ & Yes & $\begin{array}{l}\mathrm{LP}, \mathrm{HP}, \mathrm{BP}, \\
\mathrm{BR} \text {, and AP }\end{array}$ & Both \\
\hline & DDCCTA & 1 & 3 & SIMO & Yes & No & No & $\pm 5 \mathrm{~V}, \mathrm{NA}$ & $1.061 \mathrm{M}$ & Yes & $\begin{array}{l}\mathrm{LP}, \mathrm{HP}, \mathrm{BP}, \\
\mathrm{BR} \text {, and AP }\end{array}$ & Both \\
\hline [36] & DVCCCTA & 1 & - & SIMO & Yes & No & Yes & NA & $3.84 \mathrm{M} * *$ & Yes & LP, HP, and BP & Sim. \\
\hline [37] & LT1228 & 1 & 1 & MISO & No & Yes & Node $V_{i n 1}$ & $\pm 5 \mathrm{~V}, \mathrm{NA}$ & $155 \mathrm{k}$ & Yes & $\begin{array}{l}\mathrm{LP}, \mathrm{HP}, \mathrm{BP}, \\
\mathrm{BR} \text {, and AP }\end{array}$ & Both \\
\hline $\begin{array}{l}\text { This study } \\
\text { (Fig. 3(a)) }\end{array}$ & LT1228 & 2 & 2 & MISO & Yes & $\begin{array}{c}\text { Nodes HP } \\
\text { and BR }\end{array}$ & $\begin{array}{c}\text { Nodes } V_{i n 1} \\
\text { and } V_{i n 3}\end{array}$ & $\begin{array}{c} \pm 5 \mathrm{~V} \\
115 \mathrm{~mW}\end{array}$ & $144 \mathrm{k}$ & Yes & $\begin{array}{l}\mathrm{LP}, \mathrm{HP}, \mathrm{BP}, \\
\mathrm{BR} \text {, and AP }\end{array}$ & Both \\
\hline
\end{tabular}

$(\mathrm{OTA}=$ operational transconductance amplifier; AD844 = commercially available IC from Analog Devices, Inc.; CCII = second-generation current conveyor; DVCC = differential voltage current conveyor; DDCC $=$ differential difference current conveyors; FDCCII = fully differential current conveyor; CDBA = current difference buffered amplifier; VD-DIBA = voltage differencing differential inverted buffered amplifier, VDCC $=$ voltage differencing current conveyor; VDBA $=$ voltage differencing buffered amplifier; VDDDA = voltage differencing differential difference amplifier; EX-CCCII $=$ extra X current controlled conveyor; DDCCTA $=$ differential difference current conveyor transconductance amplifier; DVCCCTA = differential voltage current controlled conveyor transconductance amplifier; NA = the information not available; $\mathrm{MISO}=$ multiple-input and single-output; $\mathrm{MIMO}=$ multiple-input and multiple-output; SIMO = single-input and multiple-output; Sim. = simulation; Exp. = experiment. In this table, the supply voltage and power consumption are obtained from the experimental results. "**" means that the natural angular frequency is obtained from CMOS technology simulation.) 


\section{Conclusions}

This research describes a new configuration of a TISO VM universal filter employing two LT1228s as ABBs that can be electronically tunable. The proposed TISO universal filter can obtain the cancellation of parasitic impedance effects due to the usage of double grounded capacitors. It can generate five output filtering functions: LP, AP, BR, BP, and HP. The input voltage nodes $V_{i n 1}$ and $V_{i n 3}$ have high input impedance. The proposed filter is capable of directly cascading to other VM circuits because its output voltage node exhibits low impedance. However, it requires an inverting input voltage signal for realizing AP and BR filter responses. The natural angular frequency can be linearly and electronically tuned. The provided simulation results employing LT1228s are performed to confirm the theoretical and experimental analysis. The range of THD value is lower than $1 \%$ when the amplitude of sine wave input signal is lower than $50 \mathrm{mV}_{\mathrm{p}}$.

\section{Acknowledgements}

This research was supported by King Mongkut's Institute of Technology Ladkrabang (KMITL).

\section{Conflicts of Interest}

The authors declare no conflict of interest.

\section{References}

[1] A. S. Sedra and K. C. Smith, Microelectronic Circuits, 3rd ed., Florida: Holt, Rinehart, and Winston, 1991.

[2] M. P. P. Wai, A. Chaichana, W. Jaikla, S. Siripongdee, and P. Suwanjan, "One Input Voltage and Three Output Voltage Universal Filters with Orthogonal Tune of Frequency and Bandwidth," International Journal of Electrical and Computer Engineering, vol. 11, no. 4, pp. 2962-2973, August 2021.

[3] T. K. Paul, S. Roy, and R. R. Pal, "Tunable Lossy and Lossless Grounded Inductors Using Minimum Active and Passive Components," International Journal of Engineering and Technology Innovation, vol. 11, no. 3, pp. 171-190, June 2021.

[4] L. Safari, G. Barile, G. Ferri, and V. Stornelli, "High Performance Voltage Output Filter Realizations Using Second Generation Voltage Conveyor," International Journal of RF and Microwave Computer-Aided Engineering, vol. 28, no. 9, e21534, November 2018.

[5] S. Tuntrakool, M. Kumngern, R. Sotner, N. Herencsar, P. Suwanjan, and W. Jaikla, "High Input Impedance Voltage-Mode Universal Filter and Its Modification as Quadrature Oscillator Using VDDDAs," Indian Journal of Pure and Applied Physics, vol. 55, no. 5, pp. 324-332, May 2017.

[6] D. Biolek, R. Senani, V. Biolkova, and Z. Kolka, "Active Elements for Analog Signal Processing, Classification, Review and New Proposals," Radioengineering, vol. 17, no. 4, pp. 15-32, December 2008.

[7] Analog Devices, "AD844 Datasheet," https://www.analog.com/media/en/technical-documentation/data-sheets/AD844.pdf, 2017.

[8] Linear Technology Coporation, "LT1228 100MHz Current Feedback Amplifier with DC Gain Control," https://www.analog.com/media/en/technical-documentation/data-sheets/1228fd.pdf, 2012.

[9] S. F. Wang, H. P. Chen, Y. Ku, and Y. C. Lin, "Versatile Tunable Voltage-Mode Biquadratic Filter and Its Application in Quadrature Oscillator," Sensors, vol. 19, no. 10, 2349, September 2020.

[10] M. Kumngern, P. Suksaibul, and F. Khateb, "Four-Input One-Output Voltage-Mode Universal Filter Using Simple OTAs," Journal of Circuits, Systems, and Computers, vol. 28, no. 5, 1950078, June 2019.

[11] M. Kumngern, P. Suwanjan, and K. Dejhan, "Electronically Tunable Voltage-Mode Universal Filter with Single-Input Five-Output Using Simple OTAs," International Journal of Electronics, vol. 100, no. 8, pp. 1118-1133, August 2013.

[12] M. Parvizi, A. Taghizadeh, H. Mahmoodian, and Z. D. Kozehkanani, "A Low-Power Mixed-Mode SIMO Universal Gm-C Filter," Journal of Circuits, Systems, and Computers, vol. 26, no. 10, 1750164, March 2017.

[13] S. F. Wang, H. P. Chen, Y. Ku, and M. X. Zhong, "Analytical Synthesis of High-Pass, Band-Pass and Low-Pass Biquadratic Filters and Its Quadrature Oscillator Application Using Current-Feedback Operational Amplifiers," IEEE Access, vol. 9, pp. 13330-13343, January 2021.

[14] S. F. Wang, H. P. Chen, Y. Ku, and M. X. Zhong, "Voltage-Mode Multifunction Biquad Filter and Its Application as Fully-Uncoupled Quadrature Oscillator Based on Current-Feedback Operational Amplifiers," Sensors, vol. 20, no. 22, 6681, 2020.

[15] S. F. Wang, H. P. Chen, Y. Ku, and P. Y. Chen, "A CFOA-Based Voltage-Mode Multifunction Biquadratic Filter and a Quadrature Oscillator Using the CFOA-Based Biquadratic Filter,” Applied Sciences, vol. 9, no. 11, 2304, June 2019. 
[16] F. Yucel and E. Yuce, "Supplementary CCII Based Second-Order Universal Filter and Quadrature Oscillators," AEÜ-International Journal of Electronics and Communications, vol. 118, 153138, February 2020.

[17] T. Ettaghzouti, N. Hassen, and K. Besbes, "SIMO Type Mixed Mode Biquadratic Filter Using Second Generation Current Conveyor Circuits," 7th International Conference on Sciences of Electronics, Technologies of Information and Telecommunications, pp. 539-543, December 2016.

[18] J. W. Horng and W. Y. Chiu, "High Input Impedance Voltage-Mode Biquad with One Input and Five Outputs Employing Four CCII ICs," Indian Journal of Pure and Applied Physics, vol. 54, pp. 577-582, September 2016.

[19] A. Abaci and E. Yuce, "Second-Order Voltage-Mode Universal Filters Using Two DVCCs, Two Grounded Capacitors and Four Resistors," Journal of Circuits, Systems, and Computers, vol. 25, no. 12, 1650154, 2016.

[20] C. N. Lee, "Independently Tunable Plus-Type DDCC-Based Voltage-Mode Universal Biquad Filter with MISO and SIMO Types,” Microelectronics Journal, vol. 67, pp. 71-81, August 2017.

[21] F. Khateb, W. Jaikla, T. Kulej, M. Kumngern, and D. Kubánek, "Shadow Filters Based on DDCC," IET Circuits, Devices, and System, vol. 11, no. 6, pp. 631-637, October 2017

[22] E. Yuce, “A Single-Input Multiple-Output Voltage-Mode Second-Order Universal Filter Using Only Grounded Passive Components,” Indian Journal of Engineering and Materials Sciences, vol. 24, pp. 97-106, April 2017.

[23] C. N. Lee, "Independently Tunable Mixed-Mode Universal Biquad Filter with Versatile Input/Output Functions," AEÜ-International Journal of Electronics and Communications, vol. 70, no. 8, pp. 1006-1019, August 2016.

[24] J. K. Pathak, A. K. Singh, and R. Senani, "New Voltage Mode Universal Filters Using Only Two CDBAs," International Scholarly Research Notices, vol. 2013, 987867, 2013.

[25] M. Koksal, S. E. Oner, and M. Sagbas, "A New Second-Order Multi-Mode Multi-Function Filter Using a Single CDBA," European Conference on Circuit Theory and Design, pp. 699-702, August 2009.

[26] W. Jaikla, S. Siripongdee, F. Khateb, R. Sotner, P. Silapan, P. Suwanjan, et al., "Synthesis of Biquad Filters Using Two VD-DIBAs with Independent Control of Quality Factor and Natural Frequency," AEÜ-International Journal of Electronics and Communications, vol. 132, 153601, Janauary 2021.

[27] W. Ninsraku, D. Biolek, W. Jaikla, S. Siripongdee, and P. Suwanjan, "Electronically Controlled High Input and Low Output Impedance Voltage Mode Multifunction Filter with Grounded Capacitors," AEÜ-International Journal of Electronics and Communications, vol. 68, no. 12, pp. 1239-1246, December 2014.

[28] S. Roy, T. K. Paul, S. Maiti, and R. R. Pal, "Voltage Differencing Current Conveyor Based Voltage-Mode and Current-Mode Universal Biquad Filters with Electronic Tuning Facility," International Journal of Engineering and Technology Innovation., vol. 11, no. 2, pp. 146-160, April 2021.

[29] N. Roongmuanpha, M. Faseehuddin, N. Herencsar, and W. Tangsrirat, "Tunable Mixed-Mode Voltage Differencing Buffered Amplifier-Based Universal Filter with Independently High-Q Factor Controllability,” Applied Sciences, vol. 11, no. 20, 9606, 2021.

[30] N. Roongmuanpha, T. Pukkalanun, and W. Tangsrirat, "Practical Realization of Electronically Adjustable Universal Filter Using Commercially Available IC-Based VDBA,” Engineering Review, vol. 41, no. 3, pp. 1-9, January 2021.

[31] W. Jaikla, F. Khateb, T. Kulej, and K. Pitaksuttayaprot, "Universal Filter Based on Compact CMOS Structure of VDDDA," Sensors, vol. 21, no. 5, 1683, March 2021.

[32] S. Sangyaem, S. Siripongdee, W. Jaikla, and F. Khateb, "Five-Input Single-Output Voltage Mode Universal Filter with High Input and Low Output Impedance Using VDDDAs,” Optik, vol. 128, pp. 14-25, January 2017.

[33] P. Huaihongthong, A. Chaichana, P. Suwanjan, S. Siripongdee, W. Sunthonkanokpong, P. Supavarasuwat, et al., "Single-Input Multiple-Output Voltage-Mode Shadow Filter Based on VDDDAs," AEÜ-International Journal of Electronics and Communications, vol. 103, pp. 13-23, May 2019.

[34] D. Agrawal and S. Maheshwari, "High-Performance Electronically Tunable Analog Filter Using a Single EX-CCCII," Circuits, Systems, and Signal Processing, vol. 40, no. 3, pp. 1127-1151, September 2020.

[35] H. P. Chen, Y. S. Hwang, Y. T. Ku, and T. J. Lin, "Voltage-Mode Biquadratic Filters Using Single DDCCTA," AEÜ-International Journal of Electronics and Communications, vol. 70, no. 10, pp. 1403-1411, August 2016.

[36] C. Shankar, S. V. Singh, R. Imam, and V. A. Tikkiwal, "DVCCCTA Based High Input Impedance VM Biquad Filter by the Use of Minimum Number of Active Block and All Grounded Passive Elements," 6th International Conference on Signal Processing and Integrated Networks, pp. 1106-1111, March 2019.

[37] S. Klungtong, D. Thanapatay, and W. Jaikla, "Three-Input Single-Output Voltage-Mode Multifunction Filter with Electronic Controllability Based on Single Commercially Available IC," Active and Passive Electronic Components, vol. 2017, 5240751, 2017.

[38] S. Sangyaem, "Synthesis and Design of Five-Input Single-Output Electronically Controlled Voltage Mode Multi-Function Filter with High Input and Low Output Impedance," Master Thesis, Department of Engineering Education, Faculty of Industrial Education and Technology, King Mongkut's Institute of Technology Ladkrabang, Bangkok, 2017.

[39] “TS5A3159-EP datasheet," https://www.ti.com/lit/ds/symlink/ts5a3159-ep.pdf?ts=1636375070578, January 2006.

Copyright $($ by the authors. Licensee TAETI, Taiwan. This article is an open access article distributed under the terms and conditions of the Creative Commons Attribution (CC BY-NC) license (https://creativecommons.org/licenses/by-nc/4.0/). 